\title{
Modulation of Neural Network Activity in vitro by Cyclothiazide, a Drug That Blocks Desensitization of AMPA Receptors
}

\author{
Gregory D. Funk, ${ }^{a}$ Jeffrey C. Smith, ${ }^{b}$ and Jack L. Feldman \\ Systems Neurobiology Laboratory, Department of Physiological Science, University of California at Los Angeles, \\ Los Angeles, California 90095-1527
}

To determine whether AMPA receptor channel desensitization has a physiological role in shaping network activity by modulating signal transmission through excitatory circuits, we examined the effects of cyclothiazide (CYT), the most potent known blocker of AMPA receptor desensitization, on the behavior of an endogenously active neural system in vitro, the brainstem network generating rhythmic respiratory oscillations in neonatal rat medullary slices. Bath application of $100 \mu \mathrm{M}$ CYT significantly increased the frequency of endogenously generated rhythm and increased the amplitude of the circuit output [i.e., discharge of hypoglossal (XII) respiratory motoneurons]. Local application of CYT within the XII motor nucleus produced a concentration-dependent increase (up to $35 \%$ ) in amplitude of the motoneuron population discharge as well as an increase in the peak current $(23 \%)$ and total charge transfer of the rhythmic insplratory synaptlc drive (33\%) to Individual XII motoneurons. CYT also acted postsynaptically to increase the amplitude of spontaneous EPSCs in motoneurons. In addition, CYT produced a profound, long-term augmentation of network frequency and motor output that may be secondary to block of desensitization. These results suggest that AMPA receptor desensitization has functionally significant effects on the temporal behavior and output of the rhythmic, respiratory neural network, and, by extrapolation, on other integrative actions of the mammalian CNS.

[Key words: excitatory amino acids, non-NMDA receptors, synaptic transmission, hypoglossal motoneurons, respiratory network, brainstem]

Excitatory synaptic transmission within the vertebrate CNS is mediated primarily by NMDA and non-NMDA (AMPA and kainate) glutamate receptor channels. Non-NMDA receptors are

Received Sept. 14, 1994; revised Dec. I, 1994; accepted Dec. 21, 1994.

We thank Di. S. M. Johnson for his comments in the preparation of this manuscript, and M. Otto-Smith for excellent technical assistance. We also thank Drs. M. L. Mayer and D. K. Patneau for helpful discussions, and Drs. A. Garfinkel and S. J. Redman for informing us of the usefulness of bootstrap statistics. Cyclothiazide was a generous gift from Eli Lilly Laboratories. This work was supported by National Institutes of Health Grants HL-40959 and NS24742. G.D.F. is a Parker B. Francis Foundation Fellow.

Correspondence should be addressed to J. L. Feldman, Ph.D., Department of Physiological Science, 2927 Life Science Building, Box 951527, Los Angeles, CA 90095-1527.

"Present address: Department of Physiology, School of Medicine, University of Aukland, Private Bag 92019, Aukland, NZ.

"Present address: Laboratory of Neural Control, NINDS, NIH Building 49. Room 3A50, Bethesda, MD 20892.

Copyright $\odot 1995$ Society for Neuroscience $0270-6474 / 95 / 154046-11 \$ 05.00 / 0$ primary mediators of fast excitatory transmission, and accordingly, their kinetic properties have been the subject of intense study. A prominent feature of AMPA receptors is their rapid desensitization, the time-dependent decay of the current response in the presence of a constant concentration of (exogenously applied) agonist (see Trussell and Fischbach, 1989; Mayer et al., 1991; Vyklicky et al., 1991; Yamada and Rothman, 1992). Desensitization may modulate the time course and efficacy of endogenous excitatory transmission (Trussell and Fischbach, 1989; Mayer et al., 1991; Vyklicky et al., 1991; Yamada and Rothman, 1992). Indeed, recently discovered drugs that block desensitization, especially certain benzothiadiazides (Yamada and Rothman, 1992; Patneau et al., 1993; Trussell et al.,1993; Yamada and Tang, 1993), increase the amplitude and, in some cases, decay time constants of AMPA receptor-mediated postsynaptic currents, consistent with a role of desensitization in shaping EPSCs (Isaacson and Nicoll, 1991; Tang et al., 1991; Vyklicky et al., 1991; Thio et al., 1992; Yamada and Tang, 1992). Whether desensitization has a physiological role in regulating signal transmission in functionally active networks in the CNS, however, remains unanswered.

The onset kinetics of desensitization may be fast enough (Tang et al., 1989; Trussell and Fischbach, 1989) or may be too slow (e.g., Colquhoun et al., 1992; Hestrin, 1992) to affect unitary synaptic events. The role of desensitization may also depend on the pattern of synaptic activity (Trussell et al., 1993). At low levels of activity, glutamate (Glu) may be removed from the synapse before the onset of desensitization. With elevated activity, however, Glu may persist sufficiently for desensitization to occur. Synaptic transmission may therefore be modulated by de. sensitization (1) during synchronized multiquantal release of neurotransmitter when clearance is slowed (Trussell et al., 1993), or (2) during high-frequency synaptic activity (Smith et al., 1991a, Trussell et al., 1993). Since time constants for recovery from desensitization are long (20-70 msec) (Patneau et al., 1993; Trussell et al., 1993), depression of postsynaptic currents can occur with high frequency repetitive inputs, affecting temporal summation and limiting the frequency response of transmission.

While the effects of desensitization on AMPA receptor chan nel kinetics and individual EPSCs have been examined in detail (Vyklicky et al., 1991; Yamada and Rothman, 1992; Trussell et al., 1993), the effects of desensitization on signal transmission and behavior of endogenously active networks have not been examined. We therefore tested the role of desensitization in regulating activity of an oscillatory motor network that generates the respiratory motor pattern. This network has several advantages for the present study. (1) The network is functionally active 
and generates endogenous oscillations in isolated slice preparations from the medulla of neonatal rats (Smith et al., 1991b; Funk et al., 1993). (2) The network oscillations originate within a defined locus in the ventrolateral medulla in the slice and are transmitted via polysynaptic pathways to the output elements, i.e., the brainstem respiratory motoneurons (Smith et al., 1991; Funk et al., 1993). Generation of these oscillations and transmission of the oscillatory drive in vitro involves glutamatergic synapses mediated almost entirely by non-NMDA receptors (Greer et al., 1991; Smith et al., 1991; Funk et al., 1993); thus, the role of desensitization in modulating various parameters of network activity including cycle frequency and the amplitude of the output (i.e., amplitude of motoneuron activity) can be analyzed. (3) The network activity is endogenous so that the concentration and time course of transmitter within synaptic clefts, as well as the frequency of transmitter release, reflects that occurring in the intact nervous system. (4) The duration of the synaptic drive during each periodic burst is $>100$ times longer than endogenous unitary synaptic events, which should prolong transmitter presence within the synaptic cleft and increase the likelihood of desensitization. Furthermore, the frequency of action potential discharge $(40-50 \mathrm{~Hz}$ ) and EPSCs of neurons during rhythmic bursts of activity are high relative to estimated rate constants for recovery from desensitization. Thus, a portion of AMPA receptors may remain desensitized between consecutive EPSCs and lead to a reduction in EPSC amplitude (Trussell and Fischbach, 1989; Smith et al., 1991a; Colquhoun et al., 1992; Trussell et al., 1993) and consequent inspiratory drive. (5) A population of active respiratory motoneurons in the slice (XII motoneurons) are easily identified and spatially segregated from other circuit elements. This provides the opportunity to analyze the role of desensitization in modulating endogenous signal transmission to identified neurons with obvious behavioral correlates (i.e., modulation of the amplitude of motor activity).

We used cyclothiazide (CYT) to assess the role of desensitization in this circuit. CYT is the most potent of the benzothiadiazides that reversibly blocks AMPA receptor desensitization (Yamada and Rothman, 1992; Patneau et al., 1993; Yamada and Tang, 1993), and its potency and relative selectivity is greater than any other agent known to affect rapid desensitization including Concanavalin $\mathrm{A}$, wheat germ agglutinin, and aniracetam. CYT, in addition to blocking desensitization, may slow receptor channel deactivation in some preparations (Patneau et al., 1993; Yamada and Tang, 1993; but see Trussell et al., 1993). However, our studies are a necessary first step to determine if CYT affects endogenous signal transmission in an active network. We analyzed the effects of CYT on the temporal pattern of network activity, amplitude of functional output (motoneuron population activity), as well as the amplitude and total charge transfer of synaptic drive currents and individual spontaneous EPSCs in functionally identified motoneurons. CYT produced significant concentration-dependent augmentation of all of these parameters. It also produced a profound, longer term augmentation of network activity and signal transmission that may be secondary to the potentiation of synaptic activity. These results provide further evidence that AMPA receptor channel desensitization can modulate synaptic transmission, thereby affecting the behavior of neural networks.

\section{Materials and Methods}

Slice preparations. Experiments were performed on medullary slice preparations from 1 -4-d-old neonatal rats that retain functional respi- ratory networks. We report results obtained from 45 slices. Details of the preparation have been previously described (Smith et al., 1991b; Funk et al., 1993). Briefly, neonatal rats were anesthetized with ether, decerebrated, and the neuraxis isolated by dissection in a bath containing control artificial cerebrospinal fluid (aCSF) [(in mM) $128 \mathrm{NaCl}, 3.0$ $\mathrm{KCl}, 1.5 \mathrm{CaCl}_{2}, 1.0 \mathrm{MgSO}_{4}, 21 \mathrm{NaHCO}_{3}, 0.5 \mathrm{NaH}_{2} \mathrm{PO}_{4}$ and 30 D-glucose] equilibrated with $95 \% \mathrm{O}_{2}-5 \% \mathrm{CO}_{2}$ at $27-28^{\circ} \mathrm{C}$. The neuraxis was sectioned with a vibratome in the transverse plane starting from the rostral medulla to within $150 \mu \mathrm{m}$ of the locus containing the neuron populations generating the respiratory network oscillation (i.e., the preBötzinger Complex; see Smith et al., 1991). A single, 500-650 $\mu \mathrm{m}$ thick transverse slice extending caudally to obex was then cut and pinned down on SYLGARD elastomer in a $5 \mathrm{ml}$ recording chamber. The slice was continuously superfused $(20 \mathrm{ml} / \mathrm{min})$ first with control aCSF for $\sim 30 \mathrm{~min}$, followed by aCSF with extracellular $\mathrm{K}^{+}$concentration raised to $9 \mathrm{~mm}\left(\mathrm{aCSF}_{\mathrm{K}}{ }^{+}\right)$to maintain rhythmic output (see Funk et al., 1993). Respiratory network motor output was recorded from cut ends of XII nerve roots; respiratory activity in individual XII motoneurons was monitored with whole-cell recording techniques.

Drug application. Cyclothiazide (Lilly Research Laboratories; Indianapolis, IN) and glibenclamide (Research Biochemical; Natick, MA) were dissolved in DMSO $(20 \mathrm{~m}$ stock solution). CYT stock solution was diluted to $10-100 \mu \mathrm{M}$ for bath application or to $100 \mu \mathrm{M}$ for local application from pressure-ejection pipettes positioned superficial to the XII motor nucleus. Glibenclamide was diluted to $10 \mu \mathrm{M}$ for bath application. Maximum concentration of DMSO in the bath or injection solutions was $0.5 \%$. L-Glutamate $(2.0 \mathrm{~mm}$; Sigma; St. Louis, MO) was dissolved in $\mathrm{aCSF}_{\mathrm{K}}{ }^{+}$

To determine the effects of CYT on the entire respiratory network, CYT was applied to the bath, where it could affect respiratory interneurons (including rhythm generating neurons), premotoneurons as well as motoneurons. Cumulative dose responses were performed. The concentration of CYT was increased progressively in steps from zero to $10,20,40,60$, and $100 \mu \mathrm{M}$. Following 7 min equilibration at each dose, network burst frequency, peak amplitude of the XII motoneuron population discharge, and the total integrated population activity were averaged over an additional $3 \mathrm{~min}$. Drug concentration was then increased to the next level without an intervening washout period. Washout after the highest concentration was followed for $2 \mathrm{hr}$. The peak amplitude of the population discharge was obtained from rectified, filtered (Paynter filter, $\tau=15 \mathrm{msec}$ ) signals of XII nerve discharge; integrated activity was obtained from the area under the rectified, filtered signal. CYT dose responses were also performed in the presence of bath-applied $10 \mu \mathrm{M}$ glibenclamide. Cumulative dose responses were also performed for acetazolamide (Sigma; St. Louis, MO), a carbonic anhydrase inhibitor, using a similar protocol except concentration was increased in steps from zero to 0.1,0.2,0.4, and $1.0 \mathrm{~mm}$ (Maren, 1977; Coates et al., 1991).

To determine the effects of bath applied CYT on respiratory activity in XII motoneurons, whole-cell recordings of XII motoneurons were obtained during bath application of two levels of CYT (40 and $80 \mu \mathrm{M})$. Washout was followed for $10 \mathrm{~min}$.

To determine the effects of CYT on inspiratory drive to XII motoneurons at the premotor to XII motoneuron synapse, the site of action of CYT was limited to the XII motor nucleus through local application of drugs. Drug application was controlled via timed pressure injection (5-40 psi) from triple-barreled pipettes ( $8 \mu \mathrm{m}$ tip diameter per barrel) (Funk et al., 1993) superficial to one XII motor nucleus. Pipette tips were placed between $100-200 \mu \mathrm{m}$ from the midline to minimize diffusion of CYT to the contralateral nucleus. Pipette barrels contained $100 \mu \mathrm{M}$ CYT dissolved in $0.5 \%$ DMSO in $\mathrm{aCSF}_{\mathrm{K}}^{+}, 2.0 \mathrm{~mm}$ Glu in $\mathrm{aCSF}_{\mathrm{K}}{ }^{+}$solution, or $0.5 \% \mathrm{DMSO}$ in $\mathrm{aCSF}_{\mathrm{K}}{ }^{+}$solution.

Whole-cell recordings from XII motoneurons. Currents were recorded from 30 XII motoneurons, $150-250 \mu \mathrm{m}$ below the slice surface, with an Axopatch 1-D amplifier (Axon Instruments; $2-5 \mathrm{kHz}$ low-pass filter) using blind whole-cell recording techniques (Blanton et al., 1989). Due to the difficulty of washing out CYT, typically only one cell per slice was studied. Electrodes (3.3-4.5 $\mathrm{M} \Omega, 1.50-2 \mu \mathrm{m}$ tip size) contained $\mathrm{K}^{+}$-gluconate solution $\left[(\mathrm{mM}) 120 \mathrm{~K}^{+}\right.$-gluconate, $5 \mathrm{NaCl}, 1 \mathrm{CaCl}_{2}, 1$ $\mathrm{MgCl}_{2}, 10$ HEPES ( $N$-2-hydroxyethylpiperazine- $N^{\prime}$-2-ethanesulfonic acid; Sigma), 10 BAPTA [1,2-bis(2-aminophenoxy)ethane- $N, N, N^{\prime} N^{\prime}$-tetraacetic acid, tetra $\mathrm{K}^{+}$salt; Sigma], $2 \mathrm{ATP}\left(\mathrm{Mg}^{2+}\right.$ salt), Lucifer ycllow (dipotassium salt, 1\%; Sigma), $\mathrm{pH}$ adjusted to 7.3 using $\mathrm{KOH}$ ], and were coated with SIGMACOTE to reduce electrode capacitance. Seal resistances prior to membrane rupture ranged from $1.5-2.5 \mathrm{G} \Omega$.

Series resistance $\left(R_{s}\right)$ and whole-cell capacitance were estimated us- 
ing $100 \mathrm{~Hz},-10 \mathrm{mV}, 3.0 \mathrm{msec}$ voltage pulses. $R_{\mathrm{s}}$ compensation was $60-80 \%$. Neuron input resistance $\left(R_{N}\right)$ was calculated at $-70 \mathrm{mV}$ holding potential from the current responses to $10 \mathrm{mV}, 300 \mathrm{msec}$, hyperpolarizing voltage steps. Effects of drugs on resting membrane potential (RMP) and $R_{N}$ were determined. Membrane potentials were adjusted to correct for liquid junction potentials $\left(-10 \mathrm{mV}\right.$ for $\mathrm{K}^{+}$-gluconate solution).

Motoneuron identification. All XII motoneurons studied were functionally identified respiratory motoneurons. Selection criteria for respiratory motoncurons are described elsewhere (Funk et al., 1993). They include the presence of oscillatory synaptic drive currents in synchrony with rhythmic burst of activity in XII nerve roots; multipolar soma located in the ventral portion of XII nucleus; an axon exiting the slice in the XII nerve; stable resting membrane potentials with leakage currents $\left(I_{1 \mathrm{FAK}}\right)<100 \mathrm{pA}$ at holding potentials $\left(V_{H}\right)$ of $-70 \mathrm{mV}$; and stable access resistances $<40 \mathrm{M} \Omega$. Anatomical identification was based on Lucifer yellow labeling of neurons.

Data analysis. Intracellular signals were recorded on tape. Selected segments of data were digitized at $2-10 \mathrm{kHz} / \mathrm{channel}$ and signal amplitudes representing peak synaptic currents, integrals representing total charge transfer over the oscillatory drive current, and time course of synaptic currents were analyzed with a time signal analysis software package (RS PROBE, BBN Laboratories). Although data are presented relative to control values, all statistical tests were performed on raw data. Statistical values are reported as mean \pm SD. Differences between means were tested with ANOVA and Bonferroni simultaneous confidence intervals for multiple comparisons (RS PROBE, BBN Laboratories). Values of $p<0.05$ were assumed significant.

EPSC time constant, amplitude, and interval analysis. The time constant of smaller amplitude, single spontaneous EPSCs occurring in XII motoneurons during the expiratory period, the period between bursts of inspiratory activity, were determined before and after CYT treatment. EPSCs were filtered at $5 \mathrm{kH} z$ and analyzed off line using AXODATA/ AXOGRAPH (Axon Instruments). Single-exponential analysis of time constants was carried out for 15-20 EPSCs of varying amplitude per cell, before and after CYT. Statistical comparisons were made using the Student's $t$ test. Values of $p<0.05$ were assumed significant.

Amplitude and interval distributions of EPSCs occurring during the expiratory period were also determined before and after CYT treatment using a Vaxlab Peak-Processing algorithm (DIGITAL) that detected increasing and decreasing trends in the current records. Distributions were not Gaussian and thus were compared using Bootstrap methods for statistical inference (Efron and Tibshirani, 1993) that do not require normality. One thousand bootstrap estimates of the mean amplitude and interval before and after CYT treatment were calculated and the difference between these simulated distributions was compared using the Student's $t$ test. Values of $p<0.05$ were assumed significant.

\section{Results}

Bath-applied CYT increases network oscillatory frequency and motor output

To determine the effects of CYT on respiratory network activity, we applied CYT to the aCSF bathing the entire slice $(n=6)$ where it could affect respiratory interneurons (including rhythmgenerating neurons), premotoneurons, and motoneurons. CYT produced significant increases in the rhythmic burst frequency, and in the peak and integrated XII motoneuron population discharge (Fig. 1). At concentrations $\geq 100 \mu \mathrm{M}$, tonic activity appeared on the XII nerves, occasionally obscuring the rhythmic activity. Thus, CYT was not increased beyond $100 \mu \mathrm{M}$, which corresponds to concentrations producing maximal potentiation of synaptic activity in other preparations (Patneau et al., 1993; Yamada and Tang, 1993). During washout of CYT, burst frequency and XII burst amplitude continued to increase. The duration of this post-CYT potentiation was variable. Frequency and peak burst amplitude remained elevated for up to $2 \mathrm{hr}$. The peak amplitude of the integrated motoneuron discharge typically returned toward $100 \mu \mathrm{M}$ levels within 60 min but always remained significantly greater than control levels.

Diazoxide, a benzothiadiazide drug similar to CYT, opens
ATP-sensitive $\mathrm{K}^{\dagger}$ channels (Dunne et al., 1987; Misler et al., 1989; Quaste and Cook, 1989; Standen et al., 1989). Similar actions of CYT on medullary neurons (Mourre et al., 1989; Miller, 1990) could also affect respiratory network activity. To separate effects of CYT on AMPA receptor properties from potential effects on ATP-sensitive $\mathrm{K}^{*}$ channels, CYT dose-response curves were repeated with $10 \mu \mathrm{M}$ glibenclamide, an ATP-dependent $\mathrm{K}$ channel blocker (Schmid-Antomarchi et al., 1987; Zünckler et al., 1988) applied to the bath. Network responses to CYT were similar in the presence or absence of glibenclamide (Fig. $1 B-D ; n=3$ ).

CYT is also is also an antihypertensive and diuretic drug that inhibits carbonic anhydrase (CA). Thus, to determine whether alterations in $\mathrm{pH}$ due to blockade of CA by CYT contributed to the effects of CYT on respiratory network behavior, we examined changes in network activity following block of $\mathrm{CA}$ with $0.1-1.0$ acetazolamide (Fig. $1 E ; n=5)$. Acetazolamide $(0.1 \mathrm{~mm})$ blocks $99 \%$ of red-cell carbonic anhydrase activity (Maren, 1977); however, acetazolamide concentrations as high as $1.0 \mathrm{~mm}$ had no significant effects on network frequency or XII burst amplitude. In addition, there was no potentiation of network activity during washout of acetazolamide, as was consistently observed during washout of CYT.

To establish that the observed changes in activity were not due to DMSO, we examined the effects of $0.5 \%$ DMSO $(n=2$ preparations). No changes were observed.

\section{Synaptic drive to XII motoneurons increases with bath-applied CYT}

To determine if an increase in synaptic drive to XII motoneurons contributed to the increased XII burst amplitude, we bath-applied CYT (40 and $80 \mu \mathrm{M}$ ) while recording from XII motoneurons ( $n=5$; Fig. 2 ). During each burst of XII nerve activity, individual XII respiratory motoneurons exhibited periodic, large-amplitude, rapidly incrementing, slowly decrementing synaptic drive currents (under voltage clamp) that mirrored the time course of the integrated motoneuron population discharge (Fig. 2A). We have previously shown (Funk et al., 1993) that these synaptic drive currents are blocked by local application of the non-NMDA receptor antagonist CNQX, whereas the NMDA channel blocker MK-801 does not affect the drive currents at the holding potentials used in the present study $(-70 \mathrm{mV})$.

Bath-applied CYT produced a dose-dependent potentiation of the synaptic drive current. The responses of the motoneuron shown in Figure $2 B$ were similar to group results ( $\Gamma i g .2 C, D$ ). Peak current increased marginally at $40 \mu \mathrm{M}$ CYT, but the charge transfer during the drive current (integrated synaptic current envelope) increased to $1.17 \pm 0.11$ of control (Fig. 2D). Peak current and charge transfer increased significantly to $1.18 \pm$ 0.12 (Fig. $2 C$ ) and $1.37 \pm 0.18$ of control (Fig. $2 D$ ), respectively, at $80 \mu \mathrm{M}$ CYT. With washout, peak current and charge transfer showed further increases to $1.26 \pm 0.15$ and $1.53 \pm$ 0.20 at $5 \mathrm{~min}$, decreased to $1.07 \pm 0.02$ and $1.44 \pm 0.05$ after $10 \mathrm{~min}$, but remained elevated above control for up to $30 \mathrm{~min}$, the longest period monitored. The initial increase during washout may reflect relief from an additional inhibitory effect of CYT (see Discussion). CYT did not affect $R_{N}$ at any dose $(n=5$; control, $135 \pm 55 \mathrm{M} \Omega ; 80 \mu \mathrm{M} \mathrm{CYT,} 137 \pm 60 \mathrm{M} \Omega$ ).

\section{Locally applied CYT potentiates XII motoneuron currents}

To establish whether CYT could potentiate synaptic currents to XII motoneurons by acting on postsynaptic Glu receptors at the 


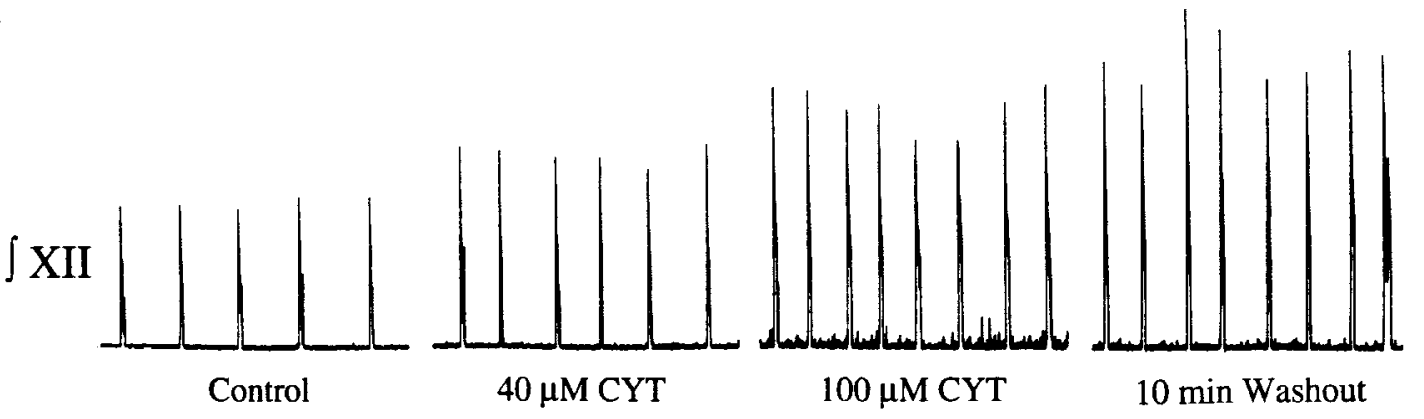

$\mathrm{B}$

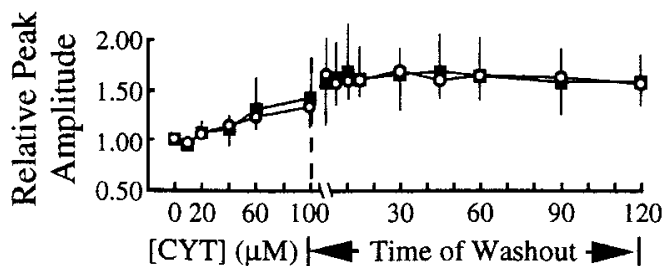

(min)

$\mathrm{D}$

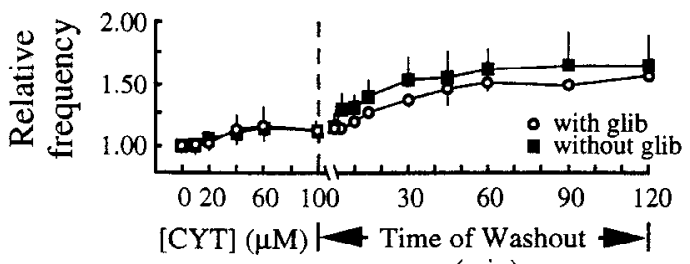

$30 \mathrm{~s}$
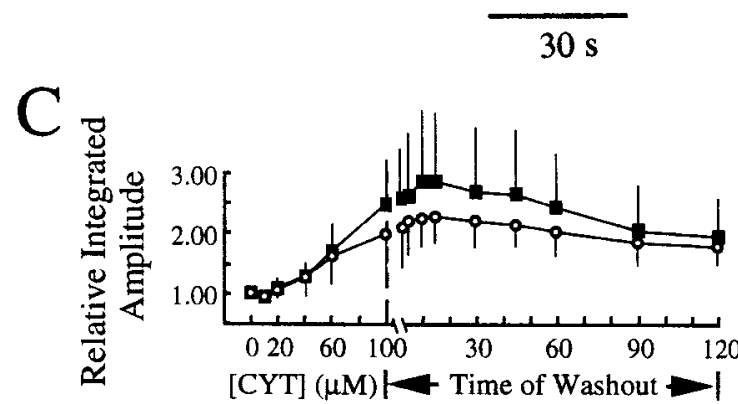

(min)
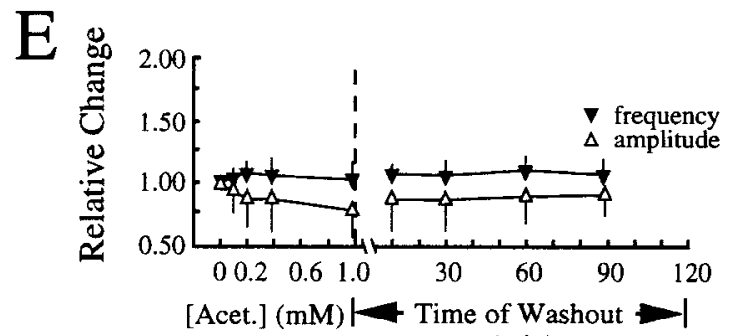

(min)

Figure 1. Potentiation of respiratory network motor output in a $650 \mu \mathrm{m}$ thick medullary slice with increasing concentrations of bath-applied CYT affecting respiratory interneurons (including rhythm-generating neurons), premotor neurons, and motoneurons. A, Traces are rectified, filtered (Paynter filter, $\tau=15 \mathrm{msec}$ ) signals of XII respiratory motoneuron population discharge recorded on XII nerve $(J X I)$ ). Cumulative dose-response relationships showing that CYT produced concentration-dependent increases in peak amplitude $(B)$, integrated amplitude $(C)$, and frequency $(D)$ of XII motoneuron discharge with (open circles, $n=3$ ) and without (closed squares, $n=6) 10.0 \mu \mathrm{M}$ glibenclamide. Long-term augmentation of motor output amplitude and frequency after washout of $100 \mu \mathrm{M}$ CYT is shown to the right of the vertical dashed line for $B-D$. $E$, Cumulative dose responses showing that acetazolamide (acet.) block of carbonic anhydrase does not affect network activity. Note that the $\mathrm{x}$-axis changes from $[C Y T]$ or $[$ Acet. $]$ to time of washout at the vertical dashed line. Vertical bars represent SD.

inspiratory premotor neuron to XII motoneuron synapse, we locally applied $100 \mu \mathrm{M}$ CYT to the XII motor nucleus while recording (1) currents induced by exogenous application of Glu with and without TTX, and (2) endogenous synaptic drive currents.

Currents induced by exogenously applied Glu: protocol I. Pressure and duration of Glu pulses $(2.0 \mathrm{~mm})$ were adjusted for each cell to produce an inward current similar in magnitude to the inspiratory drive current. Due to the depth of most recorded cells within the slice $(\geq 200 \mu \mathrm{m}$ ) and slow diffusion of Glu into and out of the tissue, however, the duration of the response to exogenous application was greater than that of the endogenous current. To account for the potential role of $0.5 \%$ DMSO in the vehicle solution, CYT/Glu (test) responses were compared to control/Glu responses. Control Glu pulses were preceded by application of $\mathrm{aCSF}_{\mathrm{K}}{ }^{1}$ containing $0.5 \%$ DMSO. Test Glu pulses were preceded by equivalent duration CYT application. Two or three control Glu pulses were delivered at 2 min intervals to ensure that the response of XII motoneurons to exogenously applied Glu was consistent. Control pulses were followed by one test pulse and several control pulses, each at 2 min intervals.

The postsynaptic response of XII motoneurons to brief control pulses of Glu was very consistent. The average standard devi ation in charge transfer per Glu pulse was only $4 \pm 9 \%(n=$ 8,2 of 8 in the presence of TTX; Fig. $3 A$ ). Application of CYT for only $5 \sec (n=6)$ increased the charge transfer per pulse to $1.78 \pm 0.98$ of control. Values returned to control $(0.98 \pm$ 0.11 ) within $2 \mathrm{~min}$ (Fig. $3 B$ ). Twenty second CYT application increased charge transfer to $5.10 \pm 2.11$ of control $(n=4$; Fig. $3 A, B)$. These effects were also completely reversible ( $\Gamma$ ig. $3 A, B)$. Six minute CYT application did not produce further potentiation $(6.36+4.36$ of control, $n=3)$ relative to 20 sec applications, although washout and recovery were markedly slowed (Fig. $3 B$ ). Glu responses remained elevated from control $(2.23 \pm 0.38)$ following $6 \mathrm{~min}$ of CYT washout.

Protocol 11 . To determine the time required for CYT to access the postsynaptic membrane and potentiate exogenous Glu responses, we established steady-state Glu currents through pro- 

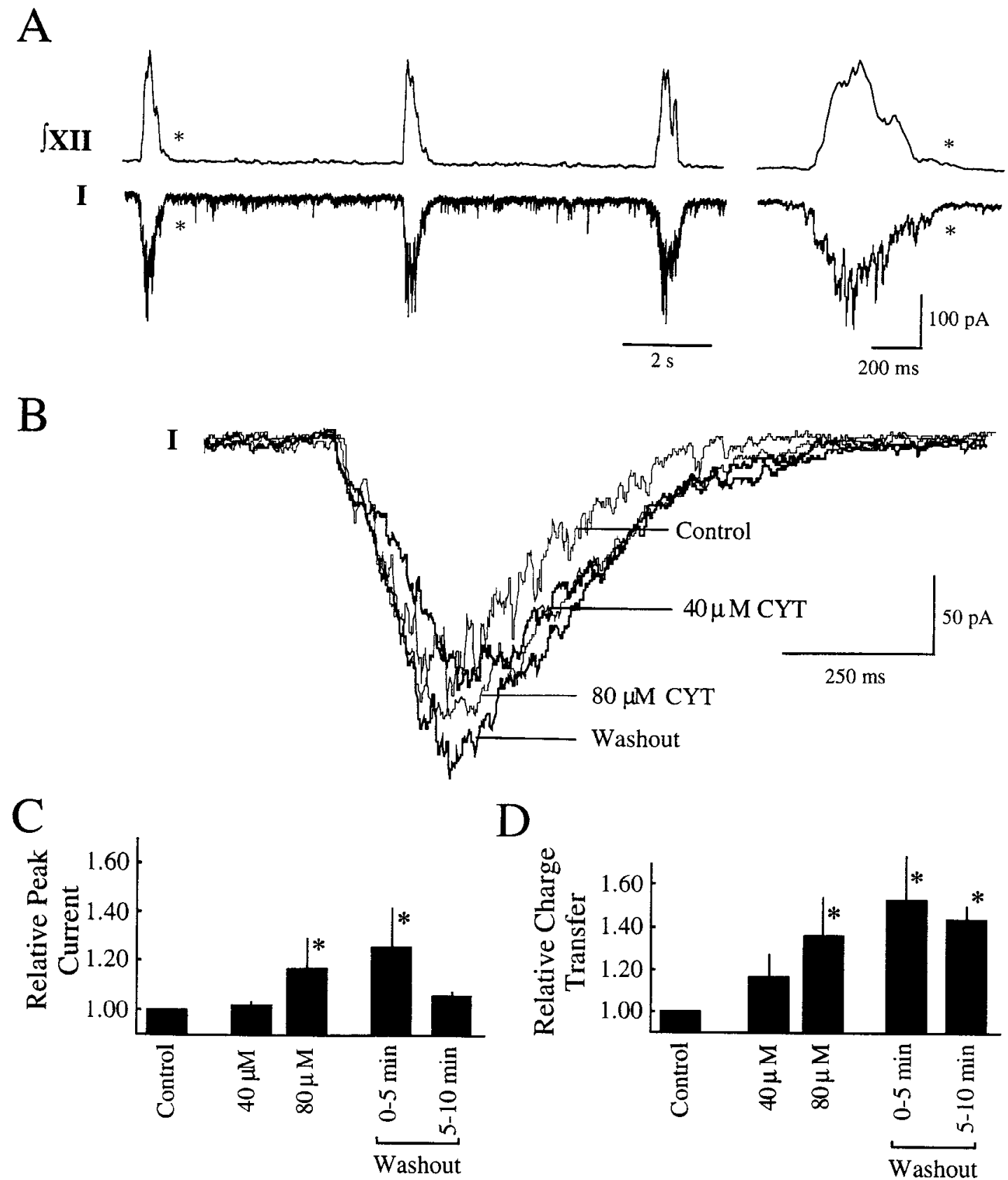

Figure 2. Potentiation of synaptic drive currents to respiratory XII motoneurons by bath-applied CYT. A, Traces illustrating relationship between integrated motoneuron population discharge $([X I I$, top trace $)$ and voltage-clamp recording of synaptic drive current $(I)$ of individual XII motoneuron (bottom trace; holding potential $V_{H}=-70 \mathrm{mV}$ ) under control conditions. The integrated motoneuron population burst and inspiratory drive current envelope marked with an asterisk are shown in expanded time scale in the right side of panel $A$. B, Voltage-clamp recordings of synaptic drive current cnvclopes ( $I$ ) from a single motoncuron prior to CYT application (control), during the last 3 min of a 10 min exposure to 40 and $80 \mu \mathrm{M}$ CYT, and during minutes 8-11 after start of CYT washout (30 drive current envelopes averaged per trace). $\left(V_{u}=-70 \mathrm{mV}, R_{s}=21 \mathrm{M} \Omega\right.$ ). $C$, Summary of dose- and time-dependent effects of CYT on peak synaptic drive currents and $(D)$ charge transfer from five motoneurons $(*$, significant difference from control; $p<0.05$ ).

longed, simultaneous application of Glu and control solution (0.5\% DMSO). Pressure ejection of control solution was then turned off and CYT simultaneously turned on until a new steady-state current was established. CYT was then turned off and control solution turned on to follow recovery (Fig. 3C). Results of experiments performed with $(n=2)$ and without ( $n$ = 1) $1.0 \mu \mathrm{M}$ TTX were similar.

The steady-state current increased to $1.36 \pm 0.04$ of control
(Fig. $3 D ; n=3$ ) $13 \pm 3.6 \mathrm{sec}$ after CYT application and returned to pre-CYT levels $14 \pm 3.0 \mathrm{sec}$ after removal of CYT.

Endogenous synaptic currents: $5-120 \mathrm{sec}$ CYT application. Since the period between consecutive inspiratory drive inputs ranged from 4-9 sec, short applications of CYT (5 sec pulses) only bracketed one cycle of synaptic drive. Thus, short pulses of CYT were timed so that the inspiratory synaptic current occurred at the end of the CYT pulse. Longer applications of 

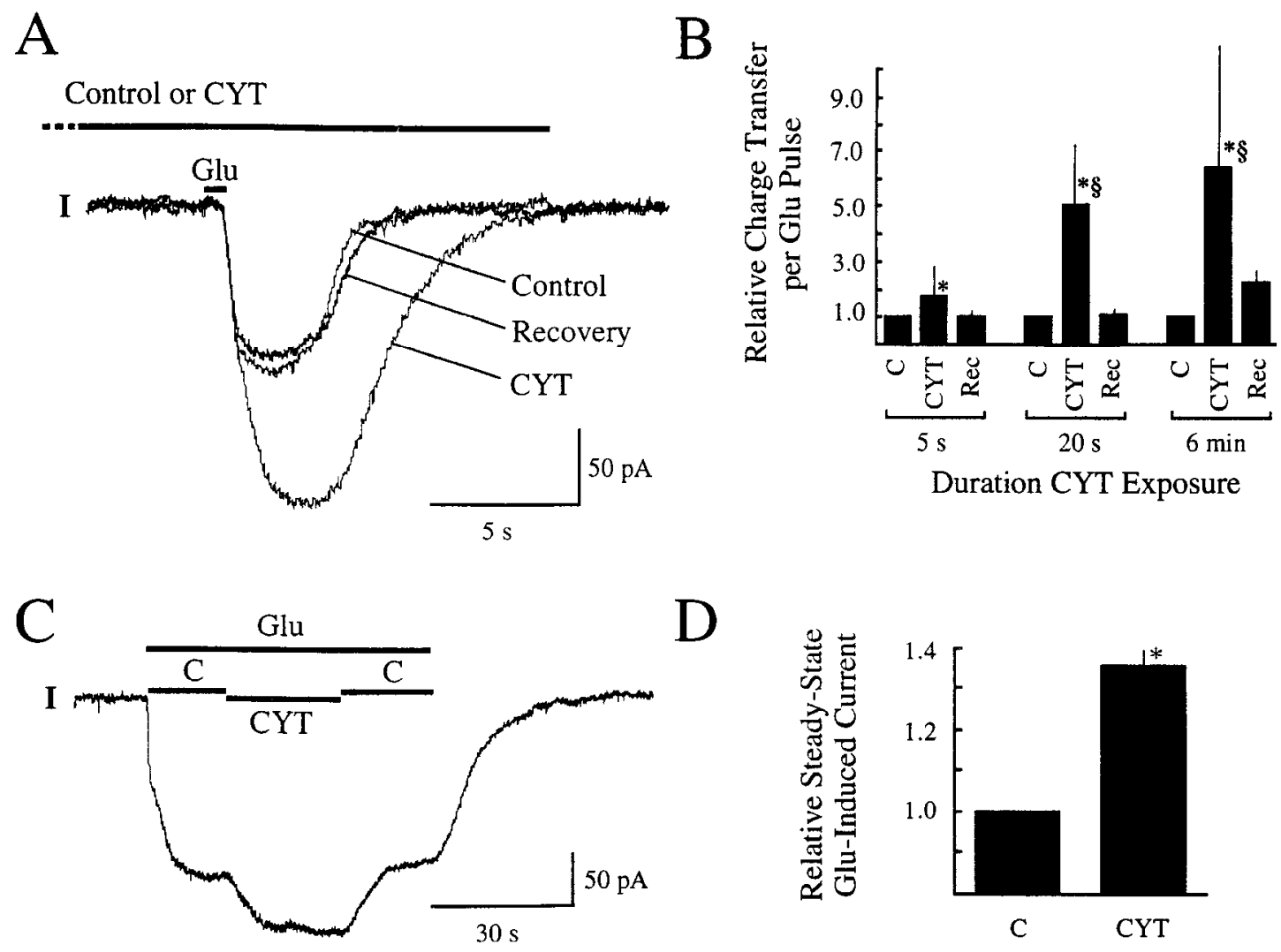

Figure 3. Potentiation of glutamate $(G l u)$-induced currents in respiratory XII motoneurons by locally applied CYT (100 $\mu \mathrm{M})$. A, Currents induced by a $500 \mathrm{msec}$ Glu pulse $(2.0 \mathrm{~mm})$ during $20 \mathrm{sec}$ application of control solution $\left(\mathrm{aCSF}_{\mathrm{K}}{ }^{+}\right.$and $0.5 \%$ DMSO; Control), during $20 \mathrm{sec}$ application of CYT, and again during $20 \mathrm{sec}$ of control solution after 2 min tecover y period fion CYT (Recovery). All currents were measured under voltageclamp $\left(V_{H}=-70 \mathrm{mV}, R_{S}=24 \mathrm{M} \Omega\right)$ with $1.0 \mu \mathrm{M}$ TTX in the perfusate. $B$, Relationship between duration of CYT application and the relative increase in charge transfer per Glu pulse $(5 \mathrm{sec}$ application, $n=6 ; 20 \mathrm{sec}$ application, $n=4 ; 6$ min application, $n=3)$. Recovery value was calculated $2 \mathrm{~min}$ after CYT application for the 5 and $20 \mathrm{sec}$ CY'I applications and after 6 min for the 6 min application to illustrate slower recovery following longer CYT exposure. $C$, Effects of locally applied CYT on steady-state Glu-induced currents in a XII motoneuron (1.0 $\mu \mathrm{M}$ TTX in bath). Local application of control solution with Glu (C; $0.5 \%$ DMSO aCSF ${ }_{\mathrm{K}}^{+}$with $2.0 \mathrm{mM}$ Glu) induced a 160 pA current that increased to 210 pA when control solution was replaced with $100 \mu \mathrm{M}$ CYT $\left(V_{t I}=-70 \mathrm{mV}\right)$. $D$. Summary of relative change in steady-state Glu-induced currents produced by $100 \mu \mathrm{M}$ CYT $(n=3)$. (*, significant difference from control, $p<0.05 ; \$$, significant difference from Glu response produced following $5 \sec$ CYT application, $p<0.05$ ).

CYT (up to $2 \mathrm{~min}$ ) bracketed several cycles allowing averaging of several drive current envelopes. Averaging provided more reliable estimates of the effects of CYT since endogenous drive currents vary from cycle to cycle. The standard deviation of the charge transfer per cycle for 10 XII motoneurons $(20$ cycles each) under control conditions averaged $24 \pm 9 \%$ of the mean value. Thus, CYT effects could be missed if only analyzing single drive current envelopes as with applications $<10 \mathrm{sec}$.

Local application of $100 \mu \mathrm{M}$ CYT for up to $2 \mathrm{~min}$ had no effect on the synaptic drive currents $(n=8$ motoneurons tested). The peak as well as the total charge transfer of the drive current envelope were unchanged by brief application of CYT.

Endogenous synaptic currents: $6 \mathrm{~min}$ CYT application. Twenty second local CYT application was sufficient for potentiation of exogenous Glu responses (Fig. 3) but insufficient for potentiation of the endogenous currents. This suggested that the endogenous inputs were mediated by a population of Glu receptors less accessible to CYT than those mediating responses to exogenous Glu. To explore this possibility, local CYT application was prolonged to $6 \mathrm{~min}$ and the effects on the synaptic drive and XII discharge amplitude were analyzed.

Six minute CYT application increased the discharge ampli- tude of the ipsilateral population of XII motoneurons to more than twice control in one slice preparation (Fig. 4A). The amplitude increased further during early washout but returned toward levels observed in the presence of CYT following $1 \mathrm{hr}$ of washout. The increase in discharge amplitude developed slowly and was highly variable (Fig. $4 B$ ), ranging from 15 to $135 \%$ after $6 \min (n=6)$. The discharge of the contralateral population of XII motoneurons (Fig. $4 B$ ) as well as the burst frequency (Fig. 4C) were not affected, indicating effects of CYT were confined to synaptic connections in the ipsilateral motor nucleus.

The effects of prolonged CYT application on the ipsilateral motoneuron synaptic drive currents are summarized in Figure $5 A-C$. Peak current and total charge transfer increased significantly in four of five cells. The increase became significant following $2 \mathrm{~min}$ application in one cell, after $5 \mathrm{~min}$ in three cells and were not significant in the remaining cell. Following 5 min CYT application, peak currents and charge transfer increased to $1.23 \pm 0.14$ and $1.33 \pm 0.15$ of control, respectively (Fig. $5 B, C$ ). Following $5 \mathrm{~min}$ of CYT washout, peak currents and charge transfer showed further significant increases in four of five cells to $1.41 \pm 0.41$ and $1.67 \pm 0.27$ of 


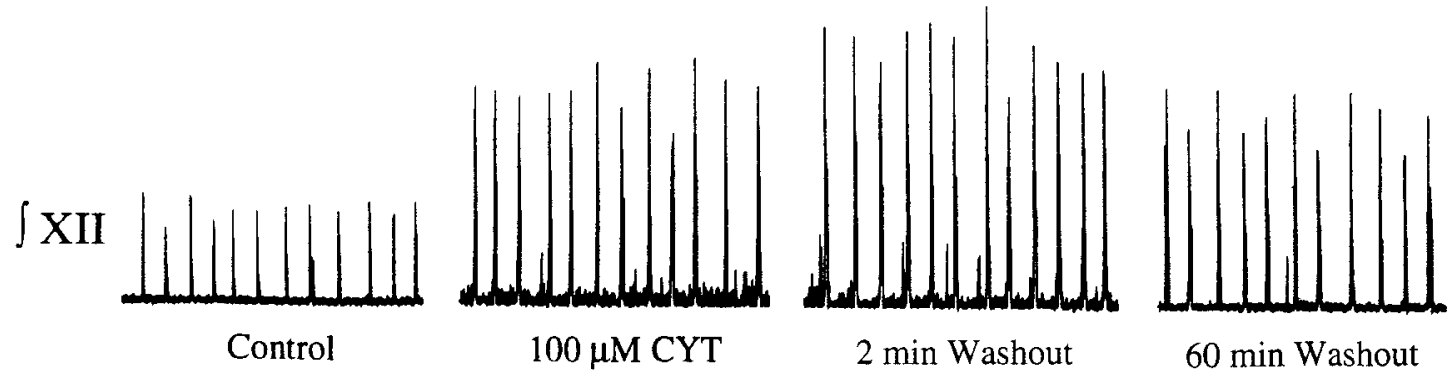

$30 \mathrm{~s}$
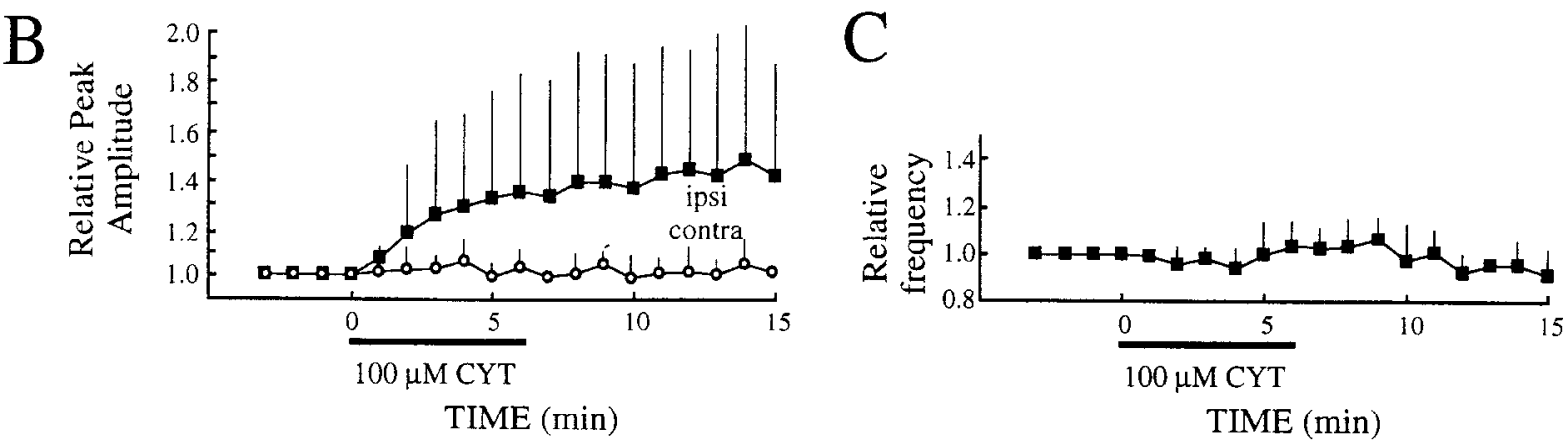

Figure 4. Augmentation of XII motoneuron population activity with prolonged local application of CYT where CYT action was timited to the inspiratory premotor to XII motoneuron synapse. A, Peak XII nerve burst amplitude increased to $135 \%$ of control after 6 min application of 100 $\mu \mathrm{M}$. CYT over ipsilateral XII motor nucleus, and increased further after washout of CYT ( 2 min washout period). Discharge amplitude remained potentiated with only slight recovery $60 \mathrm{~min}$ after start of CYT washout. Traces are rectified filtered signals of XII nerve discharge. $B$, Summary of time course of CYT effects $(100 \mu \mathrm{M}, 6 \mathrm{~min}$ application) on peak ipsi- and contralateral XII nerve discharge amplitude and $(C)$ discharge frequency $(n=6)$. CYT was applied between time 0 and $6 \mathrm{~min}$. Values were averaged over 1 min intervals. Vertical bars represent SD. Lack of effect of CYT on contralateral burst amplitude and frequency show that drug actions were confined to motoncurons under pressure-ejection pipette.

control. CYT application did not affect $R_{N}$ in any cell (control, $126 \pm 76 \mathrm{M} \Omega ; \mathrm{CYT}, 120 \pm 70 \mathrm{M} \Omega$ ).

\section{CYT potentiates individual spontaneous EPSCs}

Individual EPSCs during the inspiratory drive current could not be resolved. Thus, we examined the effects of CYT on the time constant and amplitude and interval distributions of small amplitude, spontaneous EPSCs recorded during the expiratory period (Fig. 6) (see Liu and Feldman, 1992), to determine whether CYT could potentiate individual EPSCs to XII motoneurons. The time constants of five XII motoneurons averaged $8.2 \pm 1.5$ msec prior to CYT treatment and 12.0 \pm 2.9 after CYT $(p<$ 0.05 ).

Only 2 of the 30 XII motoneurons recorded had sufficient spontaneous synaptic activity between inspiratory bursts to allow analysis of amplitude and interval distributions. We assumed that a postsynaptic site of action would alter the amplitude distribution but not the interval distribution, and presynaptic action would affect the interval distribution (Redman, 1990). In one cell, 1092 EPSCs were sampled before and after CYT; 230 EPSCs were sampled in the other. Control data were collected for 3 min prior to CYT application and test data were collected during the last $3 \mathrm{~min}$ of a $6 \mathrm{~min}$ local CYT application. CYT caused significant increases in the mean EPSC peak amplitude (Fig. $6 A-D)$ in both neurons $\left(17.3 \%\right.$ and $12.0 \% ; p<10^{-4}$ in both cases) without affecting the interval between peaks (Fig. $6 E$ ). Examples of current traces showing the maximum ampli- tude potentiation are given in Figure $6 A-C$. The amplitude distributions shown in Figure $6 D$, indicating the means, were quantified over $3 \mathrm{~min}$.

\section{Discussion}

Effects of CYT on endogenous respiratory network activity

To test for a role of AMPA receptor channel desensitization in shaping neural network activity, we examined the effects of CYT, the most potent known blocker of desensitization, on the behavior of the medullary respiratory network in vitro. CYT modulated network behavior, increased network burst frequency, pcak, and intcgrated amplitudes of the network motor output, and potentiated postsynaptic drive currents of inspiratory motoneurons. Desensitization may therefore play an important role in shaping network activity.

Generation of the respiratory network oscillations in vitro is mediated almost entirely by non-NMDA (AMPA and kainate) receptors (Greer et al., 1991; Smith et al., 1991; Funk et al., 1993). Respiratory burst frequency is reduced (monotonically) as a function of bath concentration of the competitive nonNMDA receptor antagonist CNQX, but is not perturbed by block of NMDA receptor channels (see Funk et al., 1993). Thus, the simplest explanation for the elevation of respiratory frequency is that CYT potentiates the non-NMDA receptor-mediated synaptic interactions underlying generation of respiratory rhythm.

Transmission of respiratory drive from the rhythm generating network to motoneurons depends on (multiquantal) release of 
A

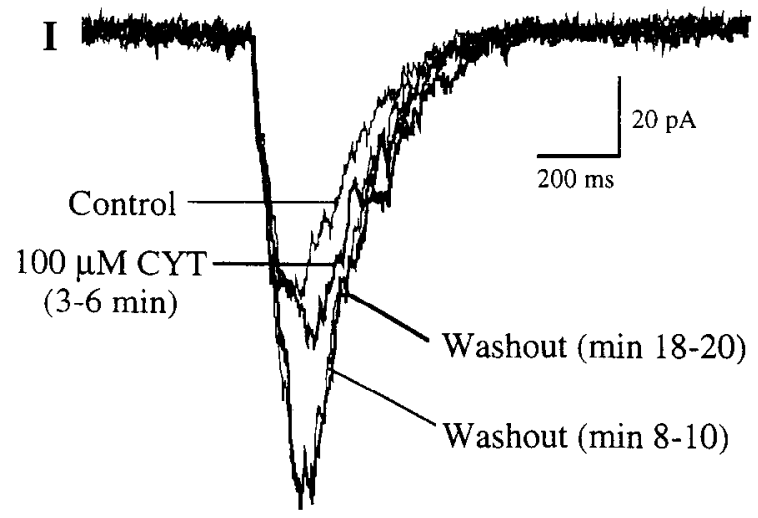

$\mathrm{B}$

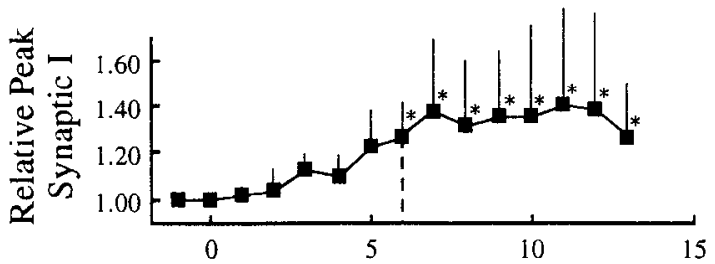

$\mathrm{C}$

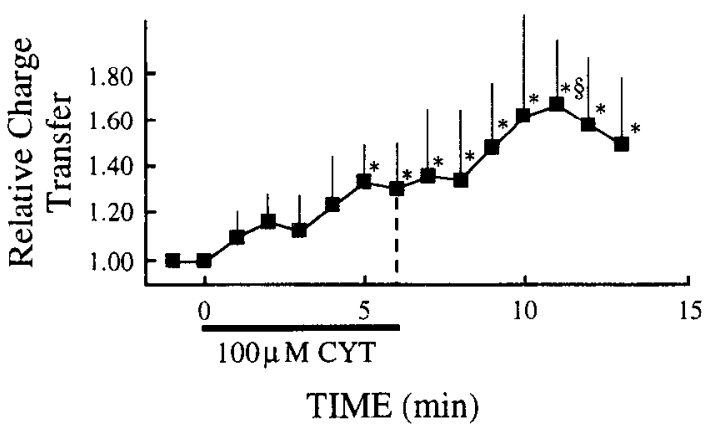

Figure 5. Effects of locally applied CYT $(100 \mu \mathrm{M})$ on endogenous synaptic drive currents to XII motoneurons. $A$, Voltage-clamp recording of synaptic current envelopes for one motoneuron prior to CYT application (control), during the last $3 \mathrm{~min}$ of a $6 \mathrm{~min}$ exposure $100 \mu \mathrm{M}$ CYT $(\mathrm{CYT})$, and at two points $(8-10 \mathrm{~min}$ and $18-20 \mathrm{~min})$ after CYT washout (20) current envelopes averaged per trace; $V_{H}=-70 \mathrm{mV}, R_{S}$ $=34 \mathrm{M} \Omega$ ). Summary of peak synaptic currents $(B)$ and total charge transfer $(C)$ before, during, and after CYT application $(n=6$ motoneurons). CYT was applied from time zero to $6 \mathrm{~min}(*$, significant difference from control; $\$$, significant difference from levels recorded at 6 min of CYT application; $p<0.05$ ).

neurotransmitter during relatively high frequency bursts at all synapses in the transmission pathway. Thus, desensitization of AMPA receptors at any synapse in the transmission pathway could affect inspiratory drive to XII motoneurons. Transmission at the last synapse in the pathway, the premotor to motoneuron synapse, is mediated alnost entirely by non-NMDA receptors (Greer et al., 1991; Funk et al., 1993). We demonstrated by local application that CYT-mediated potentiation of the endogenous synaptic drive can occur at this synapse. Locally applied CYT significantly increased: (1) the peak and integrated amplitude of the motoneuron population discharge, (2) the peak current and total charge transfer during the motoneuron postsynaptic drive current, and (3) the amplitude of spontaneous EPSCs in motoneurons via a postsynaptic action
A

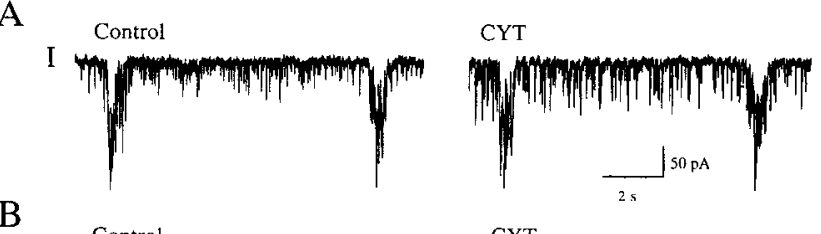

B

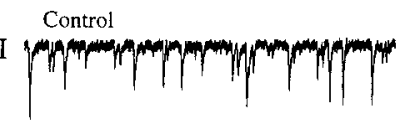

CYT

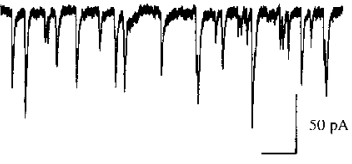

C
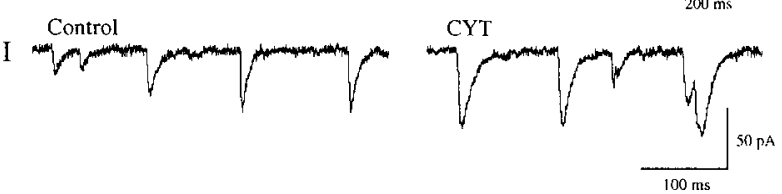

$\mathrm{D}$

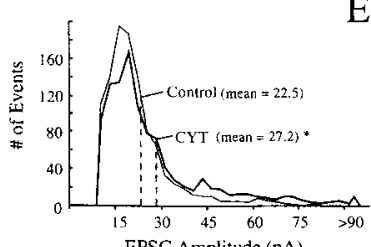

$\mathrm{E}$

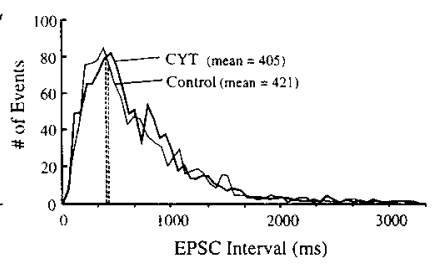

Figure 6. Effects of CYT on individual spontaneous EPSCs. A, Slow time scale current traces $(I)$ from XII motoneuron showing two large amplitude inspiratory current envelopes and small amplitude spontaneous EPSCs during expiration, the interval between the inspiratory drive inputs, before (control) and after 4 min of $100 \mu \mathrm{M}$ CYT application (CYT). Fast time scale current traces from same XII motoneuron in $A$ showing individual EPSCs $(B)$ and EPSC time course $(C)$ recorded during expiration before (control) and after $4 \mathrm{~min}$ of $100 \mu \mathrm{M}$ CYT application $(C Y T)$. D, Amplitude and $(E)$ interval distributions of spontaneous EPSCs before and after $100 \mu \mathrm{M}$ CYT application. Distributions shown are from one respiratory motoneuron under voltage-clamp $\left(V_{\prime \prime}\right.$ $=-70 \mathrm{mV} \cdot R_{\mathrm{S}}=16 \mathrm{M} \Omega$ ) and were computed from $1092 \mathrm{EPSCs}$ occurring before and during local CYT application. Bin sizes were $3 \mathrm{pA}$ and $64 \mathrm{msec}$, respectively. Mean values on figure indicate real means. Mean and SE of the means for the distributions, calculated by bootstrap statistics, were as follows: control amplitude $=22.5 \pm 0.3 \mathrm{pA} ;$ CYT amplitude $=26.6 \pm 0.5 \mathrm{pA}$; control interval $=421 \pm 12 \mathrm{msec} ;$ CYT interval $=405 \pm 11$ msec. $*$, mean amplitude values before and after CYT were significantly different at $p<10^{+}$, whereas intervals were not significantly different.

\section{Mechanisms underlying potentiation of endogenous synaptic currents}

CYT-induced increases in the net charge transfer of inspiratory drive current to motoneurons directly reflect an increase in the charge transfer of individual EPSCs underlying the drive current. Indeed, CYT potentiates individual EPSCs occurring during the expiratory period. There are multiple possible actions of CYT on receptor channel gating that could affect the charge transfer of individual EPSCs (i.e., EPSC shape), altering neuronal excitability and network activity: (1) block of rapid desensitization, (2) slowing of channel deactivation kinetics, and (3) reduction of steady-state desensitization.

We cannot establish from our single-cell measurements the relative contributions of these possible mechanism(s). Our experimental preparation, while suitable for investigating modulation of endogenous network activity, precludes detailed analysis of the effects of CYT on receptor channel kinetics, since (1) the thickness of the slice preparations, which is necessary to preserve functional respiratory networks, precludes the rapid drug application $(\mathrm{msec})$ necessary for measurement of the fast 
component of desensitization; (2) the network neurons, including the motoneurons, in the slice are morphologically complex (see Funk et al., 1993) with an unknown distribution of synaptic connections on the somatodendritic membranes, limiting precise measurement of EPSC time course; and (3) the inspiratory synaptic drives in the circuit result from temporal and spatial summation of many EPSCs, preventing resolution of single EPSCs. Nevertheless, actions of CYT on AMPA receptor channel gating and EPSC shape, and the role of desensitization in determining EPSC shape must be considered in interpreting our results.

Rapid desensitization and EPSC shape. Whether time constants for rapid desensitization are fast enough to affect the shape of individual EPSCs is controversial (see Patneau and Mayer, 1991; Tang et al., 1991; Colquhoun et al., 1992; Jonas and Sakmann, 1992b; Silver et al., 1992; Stern et al., 1992), but desensitization in some preparations appears fast enough relative to synaptic current decay rates to affect EPSC shape (e.g., Trussell and Fischbach, 1989; Tang et al., 1989; Patneau et al., 1993). In our experiments, average time constants of spontaneous EPSCs ( $\sim 8 \mathrm{msec}$ ), as estimated during the expiratory period, are sufficiently close to estimated time constants for the rapid component of desensitization (5-10 $\mathrm{msec}$; Trussell and Fischbach, 1989; Tang et al., 1991; Colquhoun et al., 1992; Hestrin, 1992; Jonas and Sakmann, 1992h; Partin et al., 1993) that desensitization could contribute to shaping individual EPSCs (Tang et al., 1989; Trussell and Fischbach, 1989; Patneau et al., 1993) and affect respiratory network activity. The increase in EPSC time constant following CYT exposure $(\sim 50 \%)$ is consistent with this thesis, with two caveats: (1) these measurements may overestimate time constants if there was poor space clamp of morphologically complex XII motoneurons; (2) although EPSCs occurring during expiration and inspiration are both dependent on non-NMDA Glu receptors (unpublished observations), extrapolations from the expiratory to inspiratory periods may not strictly apply since the expiratory and inspiratory EPSCs may involve different synapses (see Liu and Feldman, 1992).

Effects of CYT on desensitization versus deactivation. The relative contributions of desensitization block versus altered channel deactivation kinetics to CYT-induced changes in EPSC shape is controversial. CYT consistently increases the amplitude of glutamatergic EPSCs (Trussell et al., 1993; Yamada and Tang, 1993) (up to 80\%), and this can be attributed primarily to block of desensitization, whereas increases in decay time constants (up to threefold; Patneau et al., 1993; Yamada and Tang, 1993) result primarily from slowing the rate of deactivation. Both factors contribute to a net increase in charge transfer [which is approximately proportional to their product ( $\Delta$ amplitude $\times \Delta$ decay time constant)], so that both could have contributed to the CYTmediated increase in total charge transfer of the inspiratory drive current in our studies. Our findings that the EPSC amplitude distribution is altered by CYT suggests that a significant component of the increased charge transfer during the inspiratory current resulted from block of desensitization.

Steady state desensitization. If steady-state levels of Glu in the synapse correspond to levels in extracellular fluid of brain tissue (Benveniste et al., 1984; Jacobsen et al., 1985; Lerma et al., 1986), CYT could affect network behavior by reducing steady-state desensitization (Trussell and Fischbach, 1989; Thio et al., 1991; Colquhoun et al., 1992). This action may be particularly important for altering respiratory frequency, which appears to depend on a baseline level of Glu release (Greer ct al., 1991; Funk et al., 1993).
Role of kinetics of recovery from desensitization. The critical kinetic parameter underlying the effects of CYT on network behavior may be the time constant for recovery from desensitization rather than time constants for rapid desensitization and channel deactivation. Block of desensitization consistently blocks the reduction in EPSC amplitude that occurs during successive synaptic inputs (Trussell and Fischbach, 1989; Smith et al., 1991a; Colquhoun et al., 1992; Trussell et al., 1993).

The significant feature of respiratory network activity in this regard is that the rhythmic drive results from periodic bouts of high frequency bursts of synaptic inputs. Peak firing frequencies of inspiratory interneurons that drive XII motoneurons in vitro are $\sim 40-50 \mathrm{~Hz}$ (Smith et al., 1990; Johnson et al., 1994); i.e., synaptic inputs occur at $\sim 20-25 \mathrm{msec}$ intervals. Recovery from desensitization typically takes longer than $60 \mathrm{msec}$ (Trussell and Fischbach, 1989; Smith et al., 1991a; Colquhoun et al., 1992; Trussell et al., 1993). Thus, postsynaptic receptors will remain desensitized between consecutive EPSCs, and depression of EPSC amplitudes would be expected during inspiration. Such effects do not depend on onset kinetics of rapid desensitization or deactivation, and likely contribute to the potentiation of network activity by CYT in our studies.

\section{CYT potentiation of currents induced by exogenous glutamate}

Exogenous application of Glu confirmed that CYT potentiates Glu receptor-mediated responses of XII motoneurons. The 20fold greater potentiation of responses to local application of Glu compared to endogenous synaptic responses likely reflects the difference in speed of Glu application when it is synaptically released or applied with a puffer pipette. Such large differences are typical of comparisons between potentiation of peak responses to synaptic Glu or rapidly applied Glu versus potentiation of steady-state responses that are $>90 \%$ desensitized (Yamada and Rothman, 1992). Potentiation of synaptic responses and responses to exogenous application are similar if Glu is applied rapidly (Vyklicky et al., 1991; Yamada and Rothman, 1992; Yamada and Tang, 1993).

\section{Time course of onset and recovery from potentiation by cyclothiazide}

The time course of onset and recovery from the action of CYT were slow and differed for endogenous synaptic drive versus exogenously applied Glu. Slow onset and recovery rates from CYT-mediated potentiation of synaptic or exogenous currents are well documented (Patneau et al., 1993; Yamada and Tang, 1993), but the mechanism(s) are unknown.

Onset time course. In the present studies, potentiation of the response to exogenously applied Glu took $\sim 15 \mathrm{sec}$ to reach maximum. Although diffusion of CYT into the tissue to XII motoneurons $>200 \mu \mathrm{m}$ below the surface of the slice would contribute to this delay, there are other factors. The effects of CYT on isolated neurons or membrane patches, where diffusion through tissue is not involved, also develop slowly, taking between 6-8 sec (Patneau et al., 1993) and $20 \mathrm{sec}$ (Yamada and Tang, 1993) to reach maximum. The potentiating effects of CYT on endogenous synaptic drive currents were even slower in onset, taking $>2 \mathrm{~min}$, and may reflect greater difficulty of getting CYT to synaptic receptors mediating the endogenous activity than to extrasynaptic receptors.

Another potential factor contributing to the slow onset time course is that CYT appcars to havc compcting inhibitory and cxcitatory actions on endogenous synaptic currents, with inhibitory 
actions typically occurring an order of magnitude faster than potentiating effects in some preparations (Patneau et al., 1993). Thus, inhibitory effects may determine response kinetics initially, but potentiation could dominate with prolonged exposure.

The mechanism underlying this putative inhibitory effect is not known. A block of ATP-sensitive $\mathrm{K}^{+}$channels by CYT (Dunne et al., 1987; Misler et al., 1989; Quaste and Cook, 1989; Standen et al., 1989) is not the cause; we found that the ATPdependent $\mathrm{K}$ channel blocker glibenclamide (Schmid-Antomarchi et al., 1987; Zünckler et al., 1988; but see Ashford et al., 1994) did not affect the actions of CYT. We also eliminated the possibility that alterations in $\mathrm{pH}$ secondary to blockade of CA activity by CYT contribute to the effects of CYT on respiratory network behavior by demonstrating that block of $\mathrm{CA}$ activity with $0.11 .0 \mathrm{~mm}$ acetazolamide (Maren, 1977; Coates et al., 1991) has no significant effect network frequency or XII burst amplitude. Until all the effects of CYT within the CNS are known, we cannot exclude the possibility that the long latency effect of CYT on network activity is due to the effects of CYT on a process(es) other than desensitization.

Recovery and long-term enhancement of synaptic and network activity. We currently do not know the mechanism underlying the long-term enhancement of endogenous synaptic activity following removal of CYT. In outside-out patches, where complete exposure of the patch to the bathing solution optimizes washout, the mean time constant for recovery from CYT-evoked potentiation is very long ( $\sim 40 \mathrm{sec}$ time constant, Patneau et al., 1993) but effects are reversible. The time required to recover from the effects of CYT on XII motoneuron responses to exogenous Glu in our studies was also very long, and increased with duration of CYT exposure. Given sufficient time, however, effects were reversible, indicating that washout from some receptor sites occurs in our preparation. In contrast, CYT-mediated potentiation of endogenous synaptic currents showed further enhancement following removal of CYT and was not fully reversible over a $2 \mathrm{hr}$ period of washout. We speculate that the increased synaptic activity during CYT application produced secondary, longer term changes in synaptic efficacy. Endogenous modulation of desensitization may represent a novel form of synaptic plasticity at excitatory synapses (Vyklicky et al., 1991). In this regard, our results may indicate that attenuation of desensitization initiates longer term secondary changes in synaptic efficacy.

In summary, CYT has significant potentiating effects on endogenous synaptic transmission and activity of the medullary network generating respiratory motor patterns. We attribute these effects, at least in part, to block of AMPA receptor desensitization. The modulation of respiratory frequency and amplitude of motoneuron population discharge by up to $30 \%$ would have significant physiological consequences and suggests that desensitization can have an important role in modulating signal transmission and output from this neural network. In turn, regulation of AMPA receptor desensitization by a site on non-NMDA receptor-ion channel complexes, such as the novel benzodiazepine site described by Zorumski et al. (1993), may represent yet another mechanism for network modulation and synaptic plasticity. Although several actions of CYT on AMPA receptor channel gating remain unresolved, our studies show potentiation of endogenous synaptic transmission in an intact, active network underlying a basic integrative function. This is a the necessary first step in establishing a possible physiological role of desensitization in modulating the behavior of intact networks.

\section{References}

Ashford MLJ, Bond CT, Blair TA, Adelman JP (1994) Cloning and functional expression of a rat heart KATP channel. Nature 370:456459 .

Benveniste H, Drejer J, Schousboe A, Diemer NH (1984) Elevation of extracellular concentrations of glutamate and aspartate in rat hippocampus during transient cerebral ischemia monitored by intracerebral microdialysis. J Neurochem 43:1369-1374.

Blanton MG, Lo Turco JJ, Kriegstein AJ (1989) Whole-cell recordings from neurons in slices of reptilian and mammalian cerebral cortex. $\mathbf{J}$ Neurosci Methods 30:203-210.

Coates EL, Li A, Nattie EE (199I) Acetazolamide on the ventral medulla of the cat increases phrenic output and delays the ventilatory response to $\mathrm{CO}_{2}$. J Physiol (Lond) 441:433-451.

Colquhoun D, Jonas P, Sakmann B (1992) Action of brief pulses of glutamate on AMPA/kainate receptors in patches from different neurons of rat hippocampal slices. J Physiol (I ond) 458:261-287.

Dunne MJ, Illot MC, Petersen OH (1987) Interaction of diazoxide, tolbutamide and $\mathrm{ATP}^{4-}$ on nucleotide-dependent $\mathrm{K}^{+}$channels in an insulin-secreting cell line. J Membr Biol 99:215-224.

Efron B, Tibshirani RJ (1993) An Introduction to the bootstrap. New York: Chapman and Hall.

Funk GD, Smith JC, Feldman JL (1993) Generation and transmission of respiratory oscillations in medullary slices: role of excitatory amino acids. J Neurophysiol 70:1497-1515.

Greer JJ, Smith JC, Feldman JL (1991) Role of excitatory amino acids in the generation and transmission of respiratory drive in neonatal rat. J Physiol (Lond) 437:727-749.

Hestrin S (1992) Activation and desensitization of glutamate-activated channels mediating fast excitatory synaptic currents in the visual cortex. Neuron 9:991-999.

Hestrin S, Nicoll RA, Perkel DJ, Sah P (1990) Analysis of excitatory synaptic action in pyramidal cells using whole-cell recording from rat hippocampal slices. J Pliysiol (Lond) 422:203-225.

Isaacson JS, Nicoll RA (1991) Aniracetam reduces glutamate receptor desensitization and slows the decay of fast excitatory synaptic currents in hippocampus. Proc NatJ Acad Sci USA 88:10396-10940.

Jacobsen I, Sandberg M, Hamberger A (1985) Mass transfer in brain dialysis devices - a new method for the estimation of extracellular amino acid concentration. J Neurosci Methods 15:263-268.

Johnson SM, Smith JC, Funk GD, Feldman JL (1994) Pacemaker behavior of respiratory neurons in medullary slices from neonatal rat. J Neurophysiol 72:2598-2608.

Jonas P, Sakmann B (1992a) Unitary stimulus-evoked excitatory postsynaptic currents in CA3 pyramidal cells of rat hippocampal slices resolved by patch-clamp techniques. J Physiol (Lond) 446:515P.

Jonas P, Sakmann B (1992b) Glutamate receptor channels in isolated patches from CA 1 and CA3 pyramidal cells of rat hippocampal slices. J Physiol (Lond) 455:143-171.

Keller BU, Konnerth A, Yaari Y (1991) Patch clamp analysis of excitatory synaptic currents in granule cells of rat hippocampus. J Physiol (Lond) 435:275-293.

Lerma J, Herranz AS, Herreras O, Abraira V, Marrin del Rin R (1986) In vivo determination of extracellular concentration of amino acids in the rat hippocampus. A method based on brain dialysis and computerized analysis. Brain Res 384:145-155.

Liu G, Feldman JL (1992) Quantal synaptic transmission in phrenic motor nucleus. J Neurophysiol 68:1468-1471.

Liu G, Feldman JL, Smith JC (1990) Excitatory amino acid-mediated transmission of inspiratory drive to phrenic motoneurons. J Neurophysiol 64:423-436.

Maren TH (1977) Use of inhibitors in physiological studies of carbonic anhydrase. Am J Physiol 232(4):F291-297.

Mayer ML, Vyklicky L Jr, Benveniste M. Patneau DK. Williamson L (1991) Desensitization at NMDA and AMPA-kainate receptors. In: Excitatory amino acids and synaptic transmission (Wheal $\mathrm{H}$, Thomson A, eds), pp 123-140. San Diego: Academic.

Miller RJ (1990) Glucose-regulated potassium channels are sweet news for neurobiologists. Trends Neurosci 13:197-199.

Misler S, Gee WM, Gillis KD, Scharp DW, Falke LC (1989) Metabolite-regulated ATP-sensitive $\mathrm{K}^{+}$channel in human pancreatic islet cells. Diabetes 38:422-427.

Mourre C, Ben-Ari Y, Bernardi H, Fosset M, Lazdunski M (1989) Antidiabetic sulfonylureas: localization of binding sites in the brain 
and effects on the hyperpolarization induced by anoxia in hippocampal slices. Brain Res 486:159-164.

Partin KM, Patneau DK, Winters CA, Mayer ML, Buonanno A (1993) Selective modulation of desensitization at AMPA versus kainate receptors by cyclothiazide and concanavalin A. Neuron 11:1069-1082.

Patneau DK, Mayer ML (1991) Kinetic analysis of interactions between kainate and AMPA: evidence for activation of a single receptor in mouse hippocampal neurons. Neuron 6:785-798.

Patneau DK, Vyklicky L Jr, Mayer ML (1993) Hippocampal neurons exhibit cyclothiazide-sensitive rapidly desensitizing responses to kainate. J Neurosci 13:3496-3509.

Quaste U, Cook NS (1989) In vitro and in vivo comparison of two $\mathrm{K}^{+}$ channel openers, diazoxide and cromakalim, and their inhibition by glibenclamide. J Pharmacol Exp Ther 250:261-271.

Redman S (1990) Quantal analysis of synaptic potentials in neurons of the central nervous system. Physiol Rev 70(1):165-198.

Schmid-Antomarchi H, De Weille J, Fosset M, Lazdunski M (1987) The receptor for antidiabetic sulfonylureas controls the activity of the ATP-modulated $\mathrm{K}^{+}$channel in insulin-secreting cells. J Biol Chem 262:15840-15844.

Silver RA, Traynelis SF, Cull-Candy SG (1992) Rapid-time-course miniature and evoked excitatory currents at cerebellar synapses in situ. Nature 355:163-166.

Smith, DO, Franke C, Rosenheimer JL, Zufall F, Hatt H (1991a) Desensitization and resensitization rates of glutamate-activated channels may regulate motoneuron excitability. J Neurophysiol 66(4):11661175.

Smith JC, Ellenberger HH, Ballanyi K, Richter DW, Feldman JL (199/b) Pre-Bötzinger complex: a brainstem region that may generate respiratory rhythm in mammals. Science 254:726-729.

Smith JC, Greer JJ, Liu G, Feldman JL (1990) Neural mechanisms generating respiratory pattern in mammalian brainstem-spinal cord in vitro. I. Spatiotemporal patterns of motor and medullary neuron activity. J Neurophysiol 354:173-183.

Standen NB, Quayle JM, Davies NW, Brayden JE, Huang Y, Nelson MT (1989) Hyperpolarizing vasodilators activate ATP-sensitive $\mathrm{K}^{+}$ channels in arterial smooth muscle. Science 245:177-180.
Stern P, Fdwards FA, Sakmann B (1992) Fast and slow components of unitary EPSCs on stellate cells elicited by focal stimulation in slices of rat visual cortex. J Physiol (Lond) 449:247-278.

Tang C-M, Dichter M, Morad M (1989) Quisqualate activates a rapidly inactivating conductance ion channel in hippocampal neurons. Science 243:1474-1477.

Tang C-M, Shi Q-Y, Katchman A, Lynch G (1991) Modulation of the time course of fast EPSCs and glutamate channel kinetics by aniracetam. Science 254:288-290.

Thio LL, Clifford DB, Zorumski CF (1991) Characterization of quisqualate receptor desensitization in cultured postnatal rat hippocampal neurons. J Neurosci 11:3430-3441.

Thio LL, Clark GD, Clifford DB, Zorumski CF (1992) Wheat-germ agglutinin enhances EPSCs in cultures postnatal rat hippocampal neurons by blocking ionotropic quisqualate receptor desensitization. J Neurophysiol 68:1930-1938.

Trussell LO, Fischbach GD (1989) Glutamate receptor desensitization and its role in synaptic transmission. Neuron 3:209-218.

Trussell LO, Zhang S, Raman IM (1993) Desensitization of AMPA receptors upon multiquantal neurotransmitter release. Neuron 10: 11851196.

Vyklicky L Jr, Patneau DK, Mayer ML (1991) Modulation of excitatory synaptic transmission by drugs that reduce desensitization at AMPA receptors. Neuron 7:971-984.

Yamada KA, Rothman SM (1992) Diazoxide blocks glutamate desensitization and prolongs excitatory postsynaptic currents in rat hippocampal neurons. J Physiol (Lond) 458:409-423.

Yamada KA, Tang C-M (1993) Benzothiadiazides inhibit rapid glutamate receptor desensitization and enhance glutamatergic synaptic currents. J Neurosci 13:3904-3915.

Zorumski CF, Yamada KA, Price MT, Olney JW (1993) A benzodiazepine recognition site associated with the non-NMDA glutamate receptor. Neuron 10:61-67.

Zünckler BJ, Lenzen S, Manner K, Panten U, Trube G (1988) Concentration-dependent effects of tolbutamide, meglitinide, glipizide, glibenclamide and diazoxide on ATP-regulated $\mathrm{K}^{\text {currents in pan- }}$ creatic B-cells. Naunyn Schmiedebergs Arch Pharmacol 337:225230 . 